\title{
Alcohol intake in relation to body mass index and waist-to-hip ratio: the importance of type of alcoholic beverage
}

\author{
Esther Lukasiewicz ${ }^{1}$, Louise I Mennen ${ }^{1,2, *}$, Sandrine Bertrais ${ }^{1}$, Nathalie Arnault ${ }^{1}$, \\ Paul Preziosi ${ }^{1}$, Pilar Galan ${ }^{1}$ and Serge Hercberg ${ }^{1,2}$ \\ 'UMR INSERM Unit 557/INRA Unit 1 125, Institut Scientifique et Technique de la Nutrition et de l'Alimentation, \\ ISTNA/CNAM, 5 rue du Vertbois, F-75003 Paris, France: ${ }^{2}$ Unité de Surveillance et d'Epidémiologie Nutritionnelle, \\ INVS-CNAM, Paris, France
}

Submitted 28 October 2003: Accepted 23 September 2004

\begin{abstract}
Objective: Alcohol consumption may play a role in the development of obesity but the relationship between alcohol and weight is still unclear. The aim of our study was to assess the cross-sectional association of intakes of total alcohol and of specific alcoholic beverages (wine, beer and spirits) with waist-to-hip ratio (WHR) and body mass index (BMI) in a large sample of adults from all over France.

Design: Cross-sectional.

Setting: Participants were free-living healthy volunteers of the SU.VI.MAX study (an intervention study on the effects of antioxidant supplementation on chronic diseases). Subjects: For 1481 women aged 35-60 years and 1210 men aged 45-60 years, intakes of total alcohol and specific alcoholic beverages were assessed by six 24-hour dietary records. BMI and WHR were measured during a clinical examination the year after. Results: A J-shaped relationship was found between total alcohol consumption and WHR in both sexes and between total alcohol consumption and BMI in men only $(P<0.05)$. The same relationships were observed with wine $(P<0.05)$; men and women consuming less than $100 \mathrm{~g} \mathrm{day}^{-1}$ had a lower BMI (men only) and WHR than non-drinkers or those consuming more. Spirits consumption was positively associated with BMI (linear regression coefficient $\beta=0.21,95 \%$ confidence interval (CI): $0.09-0.34$ and $\beta=0.22$, 95\% CI: $0.06-0.39$ for men and women, respectively) and WHR ( $\beta=0.003,95 \%$ CI: $0.001-0.005$ and $\beta=0.003,95 \% \mathrm{CI}: 0.0002-0.006)$ in both sexes in a linear fashion. No relationship between beer consumption and BMI or WHR was found.

Conclusion: If confirmed in longitudinal studies, our results indicate that consumption of alcoholic beverages may be a risk factor for obesity.
\end{abstract}

Overweight and obesity are major health problems in developed countries and are strongly related to risk of many chronic diseases such as cardiovascular diseases and cancers ${ }^{1}$. Alcohol is the second most energy-dense macronutrient and has an appetite-enhancing effect, which may lead to an increase in energy intake, inducing an increase in body mass index (BMI) ${ }^{2,3}$. Most studies indeed report that moderate alcohol drinkers do not compensate for the energy delivered by alcohol through a decrease in non-alcohol food intake, but tend to consume more energy than non-drinkers ${ }^{2-7}$. It is also known that alcohol suppresses the oxidation of fat, thus favouring fat storage $^{8}$. Hence, we would expect to find a positive relationship between alcohol consumption and obesity. However, the links between alcohol consumption and obesity or body fat distribution are more complex and often paradoxical. In several studies, despite their higher caloric intakes, drinkers were not more obese than nondrinkers ${ }^{4,9}$. In fact, inverse associations between alcohol and BMI have been shown in women ${ }^{2,4,8,10-12}$, but results were contradictory in men ${ }^{9,11,12}$. Previous studies on the association between alcohol consumption and body fat distribution, measured as the waist-to-hip ratio (WHR), yielded inconsistent findings ${ }^{10,11,13-15}$. These contradictory findings may be explained by the consumption of different alcoholic beverages in the countries where the studies were carried out. Most studies assessing the links between specific alcoholic beverages and obesity have been conducted in the USA or Scandinavia, where beer is an important source of alcohol ${ }^{2,11,16}$. A study performed in France, where wine is the most common alcoholic beverage, reported that both wine and beer were positively associated with WHR in women, but not in men ${ }^{10}$. However, that study was limited to three 
geographical French areas and in two of them beer, and not wine, is the most common alcoholic beverage. Therefore the aim of our study was to assess the crosssectional association of total alcohol, on the one hand, and specific alcoholic beverages (wine, beer and spirits), on the other, with WHR and BMI, in a large sample of adults from all over France.

\section{Subjects and methods}

\section{Study population}

Subjects were volunteers of the SU.VI.MAX study, a randomised, double-blind, placebo-controlled primary prevention trial, which evaluated the effect of daily antioxidant supplementation (vitamin C, vitamin E, $\beta$-carotene, selenium and zinc) at nutritional doses on the incidence of cancer and ischaemic heart disease. The cohort consisted of women aged 35-60 years and men aged 45-60 years at baseline. In total 12735 subjects were included at baseline in 1994 and were followed up for 8 years. Details on recruitment and study design are given elsewhere $^{17}$. Anthropometric data were missing for 213 women and 155 men. The participants included in the present analyses are those subjects who completed six 24-hour dietary records in the year before the first clinical examination, i.e. 1268 women and 1055 men. Those subjects who had completed five records or less were excluded as we considered five records not enough to estimate alcohol intake with sufficient precision, as not all days of the week on which alcohol intake differed were covered. The general characteristics of this population did not differ from the population included in the analyses.

The SU.VI.MAX study has been approved by the ethical committee for studies on human subjects (CCPPRB no. 706) of Paris-Cochin Hospital and the Comité National Informatique et Liberté (CNIL no. 334641).

\section{Data collection}

Dietary data were collected using the Minitel telematic network. The Minitel is a small terminal used widely in France as an adjunct to the telephone. At the beginning of the study, participants received free of charge a tiny central processing unit developed specifically for the study and loaded with specialised software that allows subjects to fill out the computerised dietary record off-line and to transmit data during brief phone connections. Subjects kept a 24-hour dietary record every 2 months, i.e. six records per year. They kept the record randomly for two weekend days and four weekdays per year, so that each day of the week was covered in all seasons for the mean intake of all participants. They were helped by the conversational facilities of the software and an instruction manual for codification of foods, including photographs for estimating portion or glass sizes.

The volunteer had to record every alcoholic beverage he drank, the number of glasses and the size of the drink according to the pictures shown in the manual. The mean daily alcohol intake was estimated from six 24-hour dietary records to cover differences between days of the week and was expressed as grams of alcohol consumed per day, corresponding to the sum of alcohol consumed per day from wine, beer, spirits and cider. Furthermore, the consumption of each specific alcoholic beverage was expressed as grams of beer, wine, spirits or cider per day.

One year after inclusion and every alternate year, subjects underwent a clinical examination. Weight, height, hip and waist circumferences were measured in the second study year during a clinical examination using standardised procedures. Weight and height were measured with subjects in underwear. Based on these anthropometric measurements, BMI was calculated as weight/height ${ }^{2}\left(\mathrm{~kg} \mathrm{~m}^{-2}\right)$ and WHR as the ratio between the waist and hip circumference. These data were available for 1268 women and 1055 men.

Data on demographic, socio-economic and lifestyle variables were assessed by means of a comprehensive questionnaire, completed at the beginning of the study. The level of education was classified into three categories: primary school, secondary school or superior. Questions on physical activity covered work and leisure time: subjects were classified as practising physical activity corresponding to more than an hour of walking per day, less than an hour of walking per day or not practising physical activity at all. Participants were categorised as never smokers, ex-smokers and current smokers.

In summary, data on physical activity and other lifestyle factors were obtained at baseline, the dietary data during the first year of the study and the anthropometric data in the second study year. This means that data on alcohol consumption were collected prior to the measurement of BMI and WHR for each subject.

\section{Statistical analyses}

Data were compiled on an Alpha-VMS system using SAS and a specific database was developed for handling the data by SAS version 6.12 (SAS Institute Inc., Cary, NC, USA).

Alcohol intake variables were transformed using a log transformation before analyses because the distributions of these variables were skewed. We added 0.5 to all scores to avoid impossible log transformation.

Linear and polynomial regressions were used to estimate the effect of total alcohol or specific alcoholic beverages (independent variables) consumption on BMI and WHR (dependent variables). Possible confounders such as smoking, age, physical activity, total energy and educational level were added in the multiple linear and polynomial regression models. To study the specific effect of each beverage, additional adjustment was performed on the types of alcoholic beverage, by including the three different beverages in the same model. 
In polynomial models $\left(Y=\alpha+\beta_{1} \log X_{1}+\beta_{2}\left(\log X_{1}\right)^{2}+\right.$ $\beta_{i} X_{i}$ ), we concluded that the relationship between $Y$ and $\log X_{1}$ was J-shaped if $\beta_{2}$ was statistically significant. To visualise the results we calculated the adjusted means of BMI and WHR for four categories of alcohol consumption. It has to be noted that, although these results are easier to interpret, they do not correspond completely to those from the regression analyses because of loss of information when dividing data into categories. Thus they were used for illustrative purposes only and not as a basis for conclusions.

The analyses were performed separately for women and men.

\section{Results}

The median value for alcohol consumption was 19.9 $\mathrm{g} \mathrm{day}^{-1}$ in men and $4.8 \mathrm{~g} \mathrm{day}^{-1}$ in women. Total daily intakes of alcohol and specific beverages were higher in men than in women. There was a greater proportion of non-drinkers among women than among men (Table 1). Wine was the most commonly consumed alcoholic beverage in both sexes. Many subjects drank exclusively wine, whereas exclusive beer, cider or spirits drinkers were rare (Table 2).

A J-shaped relationship was found between total alcohol consumption and WHR in both sexes (Fig. 1) after adjustment for age, smoking, physical activity, level of education and energy intake ( $P$ for polynomial regression coefficient $<0.05$ ). Women drinking less than $12 \mathrm{~g} \mathrm{day}^{-1}$ had a lower WHR than non-drinkers or women drinking more than $12 \mathrm{~g} \mathrm{day}^{-1}$. In men, but not in women, a similar J-shaped relationship was observed between total alcohol intake and BMI $(P<0.05)$ (Fig. 2).

These associations were reflected in a J-shaped relationship between wine consumption and WHR in both sexes and between wine and BMI in men only $(P<0.05)$. The lowest WHR was seen in non-abstaining men and women consuming less than $100 \mathrm{~g} \mathrm{day}^{-1}$ (Fig. 1). Men drinking less than $100 \mathrm{~g}$ wine daily had a lower mean BMI than non-drinkers or subjects drinking more than $100 \mathrm{~g}$ daily (Fig. 2).

Spirits consumption was positively associated with WHR in both sexes in a linear fashion (linear regression coefficient $(\beta)=0.003$, 95\% confidence interval (CI): $0.001-0.005$ and $\beta=0.003,95 \%$ CI: $0.0002-0.006$ for men and women, respectively), after adjustment for previously mentioned confounding factors. Similar linear associations were observed between BMI and spirits consumption ( $\beta=0.211,95 \% \mathrm{CI}: 0.087-0.335$ and $\beta=0.224,95 \% \mathrm{CI}$ : 0.059-0.389 for men and women, respectively). This means that an increase in spirits consumption of one glass (25 g) was associated with an increase in WHR of 0.004 and in BMI of $0.3 \mathrm{~kg} \mathrm{~m}^{-2}$ in both men and women.

Neither linear nor J-shaped relationships were found between beer consumption and BMI or WHR (Figs 1 and 2).

\section{Discussion}

This study in French adults provides cross-sectional estimates of how total alcohol intake and consumption

Table 1 General characteristics of the study population according to sex*

\begin{tabular}{|c|c|c|}
\hline & Men $(n=1055)$ & Women $(n=1268)$ \\
\hline Age (years) & $52.6(4.8)$ & $47.7(6.6)$ \\
\hline Body mass index $\left(\mathrm{kg} \mathrm{m}^{-2}\right)$ & $25.0(2.95)$ & $22.8(3.6)$ \\
\hline Waist-to-hip ratio & $0.92(0.06)$ & $0.77(0.07)$ \\
\hline Alcohol consumption (g day ${ }^{-1}$ ) & $24.1(20.7)$ & $8.9(11.5)$ \\
\hline Non-drinkers excluded & $25.9(20.3)(n=981)$ & $10.9(11.9)(n=1027)$ \\
\hline Beer consumption $\left(\mathrm{g} \mathrm{day}^{-1}\right.$ ) & $39.4(82.9)$ & $9.1(34.0)$ \\
\hline Non-drinkers excluded & $102.4(106.9)(n=406)$ & $69.2(68.1)(n=167)$ \\
\hline Wine consumption $\left(\mathrm{g} \mathrm{day}^{-1}\right)$ & $215.2(193.9)$ & $80.2(110.2)$ \\
\hline Non-drinkers excluded & $238.1(190.1)(n=954)$ & $103.3(115.2)(n=984)$ \\
\hline Spirits consumption ( g day $^{-1}$ ) & $5.9(12.2)$ & $2.8(8.4)$ \\
\hline Non-drinkers excluded & $12.0(15.2)(n=514)$ & $11.3(13.9)(n=313)$ \\
\hline Total energy $\left(\mathrm{kJ} \mathrm{day}^{-1}\right)$ & $9395(2129)$ & 6876 (1645) \\
\hline Energy without alcohol ( $\mathrm{kJ}$ day $^{-1}$ ) & 8690 (2003) & $6615(1607)$ \\
\hline \multicolumn{3}{|l|}{ Regular physical activity } \\
\hline No & $289(27.4)$ & $388(30.6)$ \\
\hline Less than $1 \mathrm{~h}$ walking daily & $214(20.3)$ & $388(30.6)$ \\
\hline More than $1 \mathrm{~h}$ walking daily & $552(52.3)$ & $492(38.8)$ \\
\hline \multicolumn{3}{|l|}{ Smokers } \\
\hline Ex-smokers & $498(47.2)$ & $332(26.2)$ \\
\hline Current smokers & $169(16.0)$ & $152(12.0)$ \\
\hline \multicolumn{3}{|l|}{ Educational level } \\
\hline Primary & $266(25.2)$ & $250(19.7)$ \\
\hline Secondary & $398(37.7)$ & $522(41.2)$ \\
\hline Superior & $391(37.0)$ & $496(39.2)$ \\
\hline
\end{tabular}

*Values are means (standard deviation) for quantitative variables and numbers (frequency, \%) for qualitative variables. 
Table 2 Drinking patterns according to sex ${ }^{\star}$

\begin{tabular}{lccc}
\hline & Exclusively & Not exclusively & Total \\
\hline $\begin{array}{l}\text { Men }(n=1055) \\
\text { Teetotallers }\end{array}$ & & \\
Wine & $267(28.0)$ & $687(72.0)$ & $954(90.4)$ \\
Beer & $11(2.8)$ & $395(97.2)$ & $406(38.5)$ \\
Spirits & $9(1.7)$ & $505(98.3)$ & $514(48.8)$ \\
Women $(n=1268)$ & & & \\
Teetotallers & & & $241(19.0)$ \\
Wine & $520(52.8)$ & $464(47.2)$ & $984(77.6)$ \\
Beer & $13(7.8)$ & $154(92.2)$ & $167(13.2)$ \\
Spirits & $20(6.4)$ & $292(93.6)$ & $312(24.6)$ \\
\hline
\end{tabular}

${ }^{*}$ Values are numbers (frequency, \%).

of specific alcoholic beverages relate to BMI and WHR We found that the relationship between BMI, WHR and alcohol consumption tended to show a J-shaped curve for both sexes, which was reflected in a similar association with wine and a linear association with spirits. Beer consumption, however, did not relate to these factors.

Several limitations in our study need to be considered when interpreting these results. The assessment of alcohol intake is, as for every nutritional factor, subject to flaws. Although study subjects, and especially heavy drinkers, tend to underestimate their alcohol intake, self-reported alcohol intake is the best method available ${ }^{18}$. Furthermore, subjects of our study reported their alcohol intake as part of total food consumption over the day and no emphasis was put on alcohol consumption. Moreover, as the subjects completed the 24-hour record by Minitel, they had no direct contact with an interviewer and the assessment of intake was thus relatively anonymous. We also have to note that we studied cross-sectional relationships and we cannot draw any conclusion on their causality.
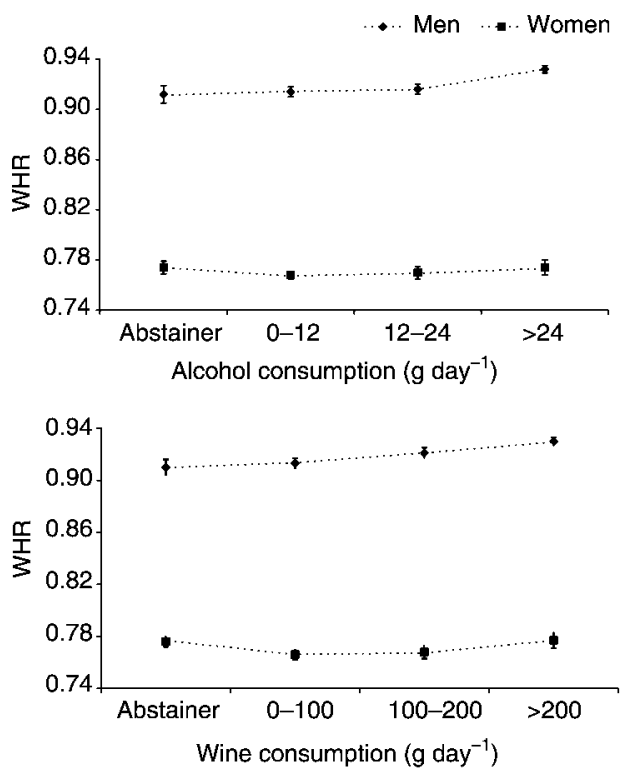

Several previous cross-sectional studies have investigated the relationship between alcohol consumption and BMI. Most of them found an inverse relationship in women $^{2,4,9-13,19-21}$. However, one study suggested a J-shaped relationship, with the highest level of alcohol intake associated with an increase in $\mathrm{BMI}^{2}$. In men, some studies have not found any relationship between alcohol consumption and $\mathrm{BMI}^{2,10,22}$, but others showed either a positive association $^{12,19,23,24}$ or an inverse one ${ }^{19,20}$. A $\mathrm{J}$-shaped relationship was reported in non-smoking men; non-drinkers and subjects with a daily intake $\geq 36 \mathrm{~g} \mathrm{dl}^{-1}$ had a higher body weight than moderate drinkers ${ }^{25}$. We confirmed this J-shaped relationship among the men of our study in the regression models, but only consumers of a very limited amount of alcohol per day had lower BMI, as the $\mathrm{J}$ shape was not really reproduced when alcohol consumption was divided in four classes. It is known that obese people in particular underestimate their intakes of specific foods and drinks ${ }^{26}$ and it is thus possible that overweight persons underestimated their alcohol intake or stopped drinking in order to reduce their energy intake. This would misleadingly induce a J-shaped relationship between BMI and alcohol. In a population where alcohol intake in general is low and the distribution is narrow, even an inverse relationship may be found.

The relationship between alcohol consumption and body fat distribution has been evaluated in several crosssectional studies. They usually found a positive association between WHR and alcohol intake ${ }^{10,11,14,22,27-29}$ except for one $^{14}$. One study among American women showed that women drinking between 2 and $7.4 \mathrm{~g} \mathrm{day}^{-1}$ had a lower WHR than non-consumers or women drinking more, suggesting a J-shaped relationship ${ }^{13}$. We have confirmed these results in our study for both women and men, but it

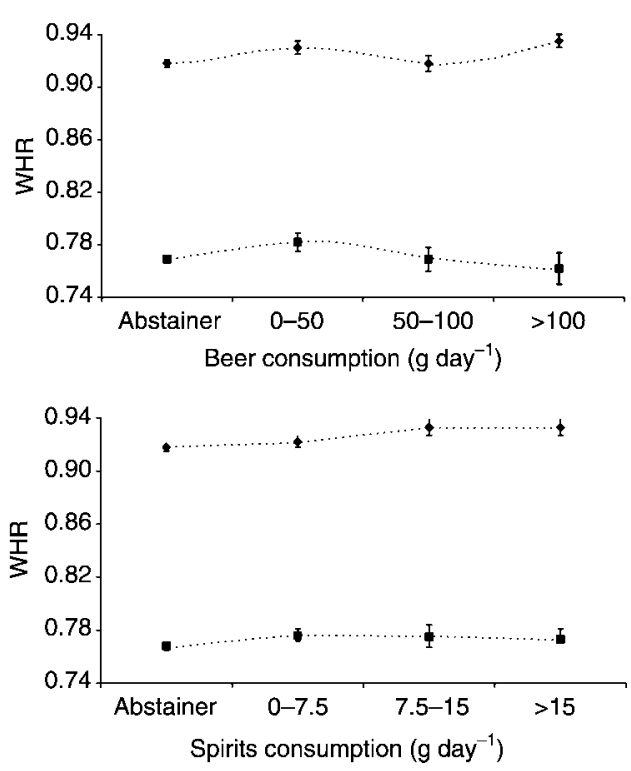

Fig. 1 Mean (95\% confidence interval) waist-to-hip ratio (WHR) according to class of total alcohol intake and type of alcoholic beverage in men and women 

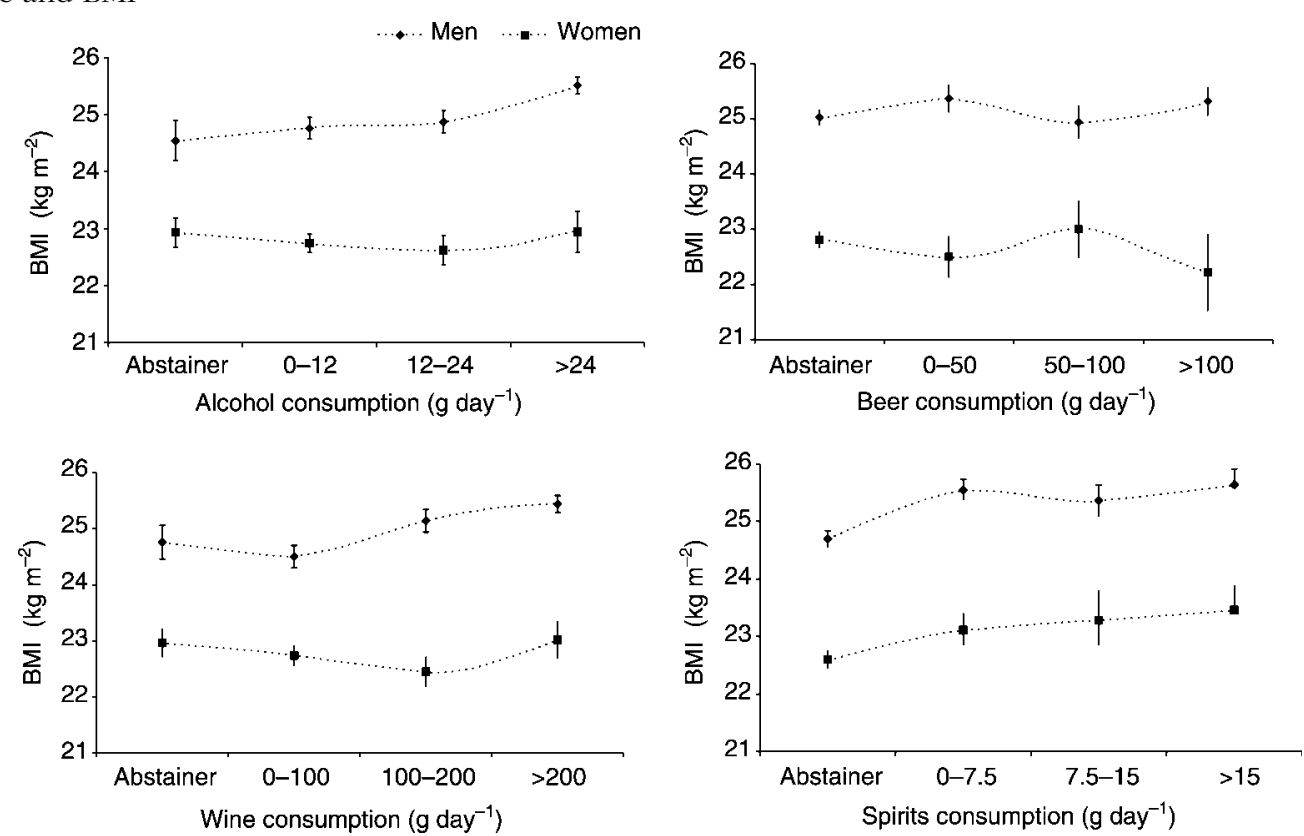

Fig. 2 Mean (95\% confidence interval) body mass index (BMI) according to class of total alcohol intake and type of alcoholic beverage in men and women

has to be noted that the same remarks on the J shape of the relationships made for the association between alcohol and BMI also apply here.

The effects of the type of alcohol on BMI or WHR were also assessed in previous studies, but the results were often contradictory. In a cohort of American people, BMI tended to increase with spirits intake in men only and was associated with neither beer nor wine ${ }^{2}$. In Finland, spirit drinkers were also shown to be heavier than other alcohol consumers $^{20}$. In a cohort of Swedish women, BMI was inversely related to wine consumption, while beer and spirits did not show any significant relationships to $\mathrm{BMI}^{16}$. Spirits consumption was usually associated with a larger WHR $^{11,27,30}$. Wine and beer were either positively ${ }^{10,11,30}$ or inversely ${ }^{16,30}$ associated or not associated at all ${ }^{10,27}$ with WHR. The absence of a relationship between beer and body fat markers in our study may be explained by the fact that, as beer consumption is not very common in France, the mean beer intake per day was too low to show an association. In fact, some studies suggest that a minimum level of alcohol intake is necessary to discover the association $^{27}$. Another French study did show a positive association between WHR and beer consumption, but that can be explained because two-thirds of the subjects were living in the only two specific areas in France where beer drinking is common.

In conclusion, our results indicate that total alcohol intake seems to be related to BMI and WHR, which is reflected in relationships between BMI and WHR and consumption of wine and spirits. This means that consumption of alcoholic beverages may be a risk factor for obesity, but this has to be confirmed in longitudinal studies.

\section{Acknowledgements}

The SU.VI.MAX Study has support from public and private sectors. Special thanks are addressed to the Centre d'Information Scientifique sur la Bière.

\section{References}

1 World Cancer Research Fund (WCRF)/American Institute of Cancer Research (AICR). Food, Nutrition and the Prevention of Cancer: A Global Perspective. Washington, DC: WCRF/AICR, 1997.

2 Colditz GA, Giovannucci E, Rimm EB, Stampfer MJ, Rosner $\mathrm{B}$, Speizer FE, et al. Alcohol intake in relation to diet and obesity in women and men. American Journal of Clinical Nutrition 1991; 54: 49-55.

3 Westerterp-Plantenga MS, Verwegen CRT. The appetizing effect of an aperitif in overweight and normal-weight humans. American Journal of Clinical Nutrition 1999; 69 : 205-12.

4 Gruchow HW, Sobocinski KA, Barboriak JJ, Scheller JG. Alcohol consumption, nutrient intake and relative body weight among US adults. American Journal of Clinical Nutrition 1985; 42: 289-95.

5 Kesse E, Clavel-Chapelon F, Slimani N, van Liere MJ. Do eating habits differ according to alcohol consumption? Results of a study of the French cohort of the European Prospective Investigation into Cancer and Nutrition (E3NEPIC). American Journal of Clinical Nutrition 2001; 74: $322-7$.

6 Tremblay A, Wouters E, Wenker M, St-Pierre S, Bouchard C, Despres JP. Alcohol and a high-fat diet: a combination favoring overfeeding. American Journal of Clinical Nutrition 1995; 62: 639-44.

7 Jéquier E. Alcohol intake and body weight: a paradox. American Journal of Clinical Nutrition 1999; 69: 173-4.

8 Prentice AM. Alcohol and obesity. International Journal of Obesity and Related Metabolic Disorders 1995; 19(Suppl. 5): S44-50. 
9 Jones BR, Barrett-Connor E, Criqui M, Holdbrook MJ. A community study of calorie and nutrient intake in drinkers and nondrinkers of alcohol. American Journal of Clinical Nutrition 1982; 35: 135-9.

10 Dallongeville J, Marecaux N, Ducimetière P, Ferrieres J, Arveiler D, Bingham A, et al. Influence of alcohol consumption and various beverages on waist girth and waist-to-hip ratio in a sample of French men and women. International Journal of Obesity and Related Metabolic Disorders 1998; 22: 1178-83.

11 Slattery ML, McDonald A, Bild DE, Caan BJ, Hilner JE, Jacobs DR Jr, et al. Associations of body fat and its distribution with dietary intake, physical activity, alcohol, and smoking in blacks and whites. American Journal of Clinical Nutrition 1992; 55: 943-9.

12 Fisher M, Gordon T. The relation of drinking and smoking habits to diet: the Lipid Research Clinics Prevalence Study. American Journal of Clinical Nutrition 1985; 41: 623-30.

13 Kaye SA, Folsom AR, Prineas RJ, Potter JD, Gapstur SM. The association of body fat distribution with lifestyle and reproductive factors in a population study of postmenopausal women. International Journal of Obesity 1990; 14 583-91.

14 Haffner SM, Stern MP, Hazuda HP, Pugh J, Patterson JK, Malina R. Upper body and centralized adiposity in Mexican Americans and non-Hispanic whites: relationship to body mass index and other behavioral and demographic variables. International Journal of Obesity 1986; 10: 493-502.

15 Lapidus L, Bengtsson C. Regional obesity as a health hazard in women - a prospective study. Acta Medica Scandinavica. Supplementum 1988; 723: 53-9.

16 Rosmond R, Bjorntorp P. Psychosocial and socio-economic factors in women and their relationship to obesity and regional body fat distribution. International Journal of Obesity and Related Metabolic Disorders 1999; 23: 138-45.

17 Hercberg S, Galan P, Preziosi P, Bertrais S, Mennen L, Malvy $\mathrm{D}$, et al. The SU.VI.MAX study: a randomised, placebocontrolled trial of the health effects of antioxidant vitamins and minerals. Archives of Internal Medicine 2004; in press.

18 Midanik LT. Validity of self-reported alcohol use: a literature review and assessment. British Journal of Addiction 1988, 83: 1019-30.

19 Williamson DF, Forman MR, Binkin NJ, Gentry EM, Remington PL, Trowbridge FL. Alcohol and body weight in United States adults. American Journal of Public Health 1987; 77: 1324-30.
20 Mannisto S, Uusitalo K, Roos E, Fogelholm M, Pietinen P. Alcohol beverage drinking, diet and body mass index in a cross-sectional survey. European Journal of Clinical Nutrition 1997; 51: 326-32.

21 Liu S, Serdula MK, Williamson DF, Mokdad AH, Byers T. A prospective study of alcohol intake and change in body weight among US adults. American Journal of Epidemiology 1994; 140: 912-20.

22 Randrianjohany A, Balkau B, Cubeau J, Ducimetiere P, Warnet JM, Eschwege E. The relationship between behavioural pattern, overall and central adiposity in a population of healthy French men. International Journal of Obesity and Related Metabolic Disorders 1993; 17: 651-5.

23 Kromhout D. Energy and macronutrient intake in lean and obese middle-aged men (the Zutphen study). American Journal of Clinical Nutrition 1983; 37: 295-9.

24 Thomson M, Fulton M, Elton RA, Brown S, Wood DA, Oliver MF. Alcohol consumption and nutrient intake in middleaged Scottish men. American Journal of Clinical Nutrition 1988; 47: 139-45

25 Meyer R, Suter PM, Vetter W. [Alcohol - risk factor for overweight]. Schweizerische Rundschau für Medizin Praxis 1999; 88: 1555-61.

26 Lafay L, Mennen L, Basdevant A, Charles MA, Borys JM, Eschwege $\mathrm{E}$, et al. Does energy intake underreporting involve all kinds of food or only specific food items? Results from the Fleurbaix Laventie Ville Sante (FLVS) study. International Journal of Obesity and Related Metabolic Disorders 2000; 24: 1500-6.

27 Lapidus L, Bengtsson C, Hallstrom T, Bjorntorp P. Obesity, adipose tissue distribution and health in women - results from a population study in Gothenburg, Sweden. Appetite 1989; 13: 25-35.

28 Laws A, Terry RB, Barrett-Connor E. Behavioral covariates of waist-to-hip ratio in Rancho Bernardo. American Journal of Public Health 1990; 80: 1358-62.

29 Keenan NL, Strogatz DS, James SA, Ammerman AS, Rice BL. Distribution and correlates of waist-to-hip ratio in black adults: the Pitt County Study. American Journal of Epidemiology 1992; 135: 678-84.

30 Duncan BB, Chambless LE, Schmidt MI, Folsom AR, Szklo M, Crouse JR 3rd, et al. Association of the waist-to-hip ratio is different with wine than with beer or hard liquor consumption. Atherosclerosis Risk in Communities Study Investigators. American Journal of Epidemiology 1995; 142 $1034-8$. 